\title{
Effect of nitridation temperature on $\mathrm{TiO}_{2}$ nanotubular structure and its photoelectrochemical performance
}

\author{
T. Lemes ${ }^{*}$,S. Khan ${ }^{2}$, E. Leal da Silva ${ }^{1}$, L. L. de Costa $^{3}$, S. R. Teixeira ${ }^{2}$, C. Aguzzoli ${ }^{4}$, C.F. \\ Malfatti $^{1}$ \\ ${ }^{1}$ LAPEC/PPGE3M, Universidade Federal do Rio Grande do Sul, Av. Bento Gonçalves, 9500, setor 4, prédio 43427, sala \\ 232 - 91501-970 - Porto Alegre/RS (Brazil) \\ ${ }^{2}$ Instituto de Física, Universidade Federal do Rio Grande do Sul, Av. Bento Gonçalves, 9500, Sala, L216, 91501-970 - \\ Porto Alegre/RS (Brazil) \\ ${ }^{3}$ LDTM/PPGE3M, Universidade Federal do Rio Grande do Sul, Av. Bento Gonçalves, 9500, setor 6, Centro de Tecnologia, \\ CEP 91501-970 - Porto Alegre/RS (Brazil) \\ ${ }^{4}$ PGMAT/UCS, Universidade de Caxias do Sul, Rua Francisco Getúlio Vargas, 1130 - Caxias do Sul, RS, Brasil \\ Phone/Fax number: +55 5133089406 , \\ *e-mail: lemes_thais@hotmail.com, celia.malfatti@ufrgs.br
}

\begin{abstract}
To improve light absorption in the visible region and to improve photoelectrochemical (PEC) response; herein, we have presented the doping of titanium dioxide $\left(\mathrm{TiO}_{2}\right)$ nanotubes with nitrogen. $\mathrm{TiO}_{2}$ nanotubes have been heat treated under the ammonia environment at different temperatures for $3 \mathrm{~h}$. The characterization was carried out using field emission gun scanning electron microscopy, (FEG-SEM), visible ultraviolet (UV-Vis) spectrophotometry. The photoelectrochemical tests of the samples were carried out in a $\mathrm{Na}_{2} \mathrm{~S} / \mathrm{Na}_{2} \mathrm{SO}_{3}(\mathrm{aq})$ solution. It was found that the nitrogen doping of titanium dioxide in temperature above 600 ${ }^{\circ} \mathrm{C}$ collapses the tubular structure and decreases the PEC performance. On the other hand, PEC performance improving was obtained from the sample nitrided at the lower temperatura which is related to the formation of lower defects in the structure of $\mathrm{TiO}_{2}$ nanotubes.
\end{abstract}

\section{Key words}

Anodizing, Nanotubes, Titanium dioxide,

Photoelectrocatalysis, Nitridation

\section{Introduction}

Increasing environmental problems, limiting fossil resources and geopolitical dependence on oil are enormous challenges for our society. The problems of increasing energy demand and the population growth [1] warrant to develop systems producing renewable energy that is abundant, emission-free and sustainable. In this context, the most interesting way is to convert solar energy to other forms of energy, since the Sun constantly bombards a sufficient energy to sustain society over any foreseeable future [2]. Solar to hydrogen production is a promising way to convert solar energy into hydrogen fuel. It is a clean mechanism that offers great potential to meet clean energy requirements [3]. The use of hydrogen as an energy source can contribute to the balance of the energy matrix and alleviate dependence on polluting energy sources. In photoelectrochemical hydrogen production, an adequate semiconductor is used that is stable and is capable of water splitting reaction. It is necessary to develop materials that exhibit high photo-induced catalytic activity and high surface area, once the photocatalytic reactions occur on the surface of the electrodes [3], [4]. In recent years, the use of nitrogen-doped titanium dioxide $\left(\mathrm{TiO}_{2}\right)$ nanotubes have attracted significant technological and scientific interest because of their unique properties, such as large specific surface area, and excellent photoelectrochemical activities.

Titanium dioxide $\left(\mathrm{TiO}_{2}\right)$ is a semiconductor with a bandgap of $\sim 3.2 \mathrm{eV}$; therefore, it can only be excited by UV light (wavelength $<380 \mathrm{~nm}$ ). It has been found that $\mathrm{N}$ doping of $\mathrm{TiO}_{2}$ is a promising approach to improve light absorption and photocatalytic performance [1]. In order to improve its absorption towards the visible light region and to obtain a good photocatalytic performance, it is interesting to dope it with nitrogen. In this way, the oxygen of $\mathrm{TiO}_{2}$ is replaced by nitrogen, which causes its valence state to be altered by decreasing the bandgap of $\mathrm{TiO}_{2}$, thereby, increasing the light absorption to the visible region [5], [6], [7].

In this work, we present a study on the doping of titanium dioxide $\left(\mathrm{TiO}_{2}\right)$ nanotubes with nitrogen and investigate photoelectrochemical response of titanium dioxide $\left(\mathrm{TiO}_{2}\right)$ nanotubes doped with nitrogen by varying the nitridation temperature. The samples were characterized by scanning electron microscopy with field emission gun (FEG-SEM), visible ultraviolet (UV-VIS) spectrophotometry. The Photoelectrochemical measurements are performed in a redox couple of $\mathrm{Na}_{2} \mathrm{~S} / \mathrm{Na}_{2} \mathrm{SO}_{3}$.

\section{Materials and methods}




\section{A. Preparation and characterizations}

To obtain modified crystalline structures the as-anodized amorphous $\mathrm{TiO}_{2}$ nanotubes [8] were doped with nitrogen, by heat treatment under ammonia environment that was carried out in a muffle furnace (SANCHIS). The nitridation was carried out at $400^{\circ}, 500^{\circ}$ and $600{ }^{\circ} \mathrm{C}$ at a flux rate of $100 \mathrm{~mL} / \mathrm{min}$ of gas mixture $\left(5: 95, \mathrm{NH}_{3}\right.$ : Ar). The heating and cooling rate of the furnace was fixed to $10{ }^{\circ} \mathrm{C} / \mathrm{min}$. In order to obtain the bandgap energy value, UV-Vis diffuse reflectance spectrophotometry was performed using Agilent Cary 5000 spectrophotometer equipped with integrating sphere accessory. The diffused reflectance was transformed to the absrorbtion using Kubelka Munk function [9]. The field emission gun-scanning electron microscopy (FEGMEV) images were obtained by the microscope MIRA3 by TESCAN operated at $15 \mathrm{kV}$. Photoelectrochemical behavior was evaluated by linear sweep voltammetry at a sweep rate of $10 \mathrm{mV} / \mathrm{s}$ by chopping the incident light in the time interval of $5 \mathrm{sec}$ in dark and under light illumination. $\mathrm{TiO}_{2}$ nanotubes were used as working electrode, $\mathrm{Pt}$ wire as the counter electrode and $\mathrm{Ag} / \mathrm{AgCl}$ as a reference electrode. These measurements were performed using potentiostat (AUTOLAB, model PGSTAT 100N) in an aqueous solution of $0.35 \mathrm{M}$ de $\mathrm{Na}_{2} \mathrm{SO}_{3}$ e $0.24 \mathrm{M}$ de $\mathrm{Na}_{2} \mathrm{~S}$. The Xe-lamp (Oriel) was used as a light source and the incident light was filtered through AM 1.5G filter and the intensity was calibrated to $100 \mathrm{~mW} \cdot \mathrm{cm}^{-2}$ (1 Sun) using a photodiode of know responsivity.

\section{Results and discussion}

Figure 1 displays the FEG-SEM images of the sample before and after the heat treatment at $500{ }^{\circ} \mathrm{C}$ under the ammonia gas flux. It can be seen that the top of the tubes before the nitridation process is smooth, however, after nitridation the structure is modified. The top seems rougher. Unlike the literature where nanotubes at $500{ }^{\circ} \mathrm{C}$ under air environment does not show any morphological change here we can observe a significant change [10]. This can be related to the modification of the $\mathrm{TiO}_{2}$ structure. In addition, in the literature for other materials such changes are also observed due to the nitridation process itself and these changes are related to the density difference that occurs due to nitrogen doping and hence material exhibit different density after nitridation as compared to its starting oxide material [10].
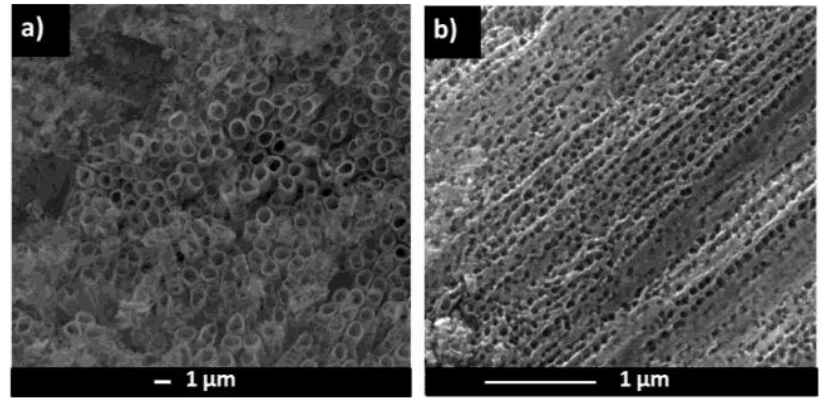

Figure 1: FEG-SEM images of the nanotubes a) before and b) after the heat treatment at $500{ }^{\circ} \mathrm{C}$ under de $\mathrm{NH}_{3}$ environment.
In order to calculate the bandgap and to understand the influence of $\mathrm{N}$-doping on the absorption properties of $\mathrm{TiO}_{2}$ nanotubes UV-VIS absorbance measurements were performed from the samples doped with nitrogen at different temperatures during the heat treatment in $\mathrm{NH}_{3}$ atmosphere for $3 \mathrm{~h}$. In figure 2 we can see that the nitridation temperature clearly affects the absorption properties of $\mathrm{TiO}_{2}$ nanotubes. The sample doped with nitrogen at $500{ }^{\circ} \mathrm{C}$ presented higher absorbance in comparison to the other temperatures. Interestingly, the sample doped with nitrogen at $600{ }^{\circ} \mathrm{C}$ presented a lower order absorbance along with an abrupt increase in absorption towards lower energy values. These results show that upon increasing the heat treatment temperature, intermediate states are generated in the bandgap of $\mathrm{TiO}_{2}$. Depending on the position of these states inside the bandgap they may either enhance or decrease the photoelectrochemical performance from these samples [3].

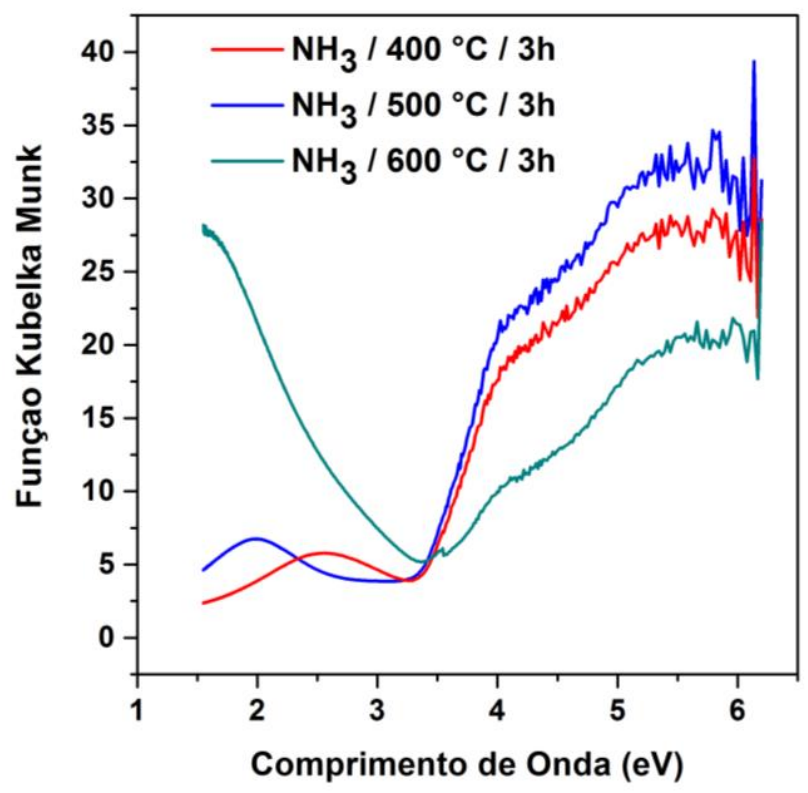

Figure 1: UV-VIS spectra of samples treated under $\mathrm{NH}_{3}$ atmosphere at different temperatures.

The literature reports $\mathrm{TiO}_{2}$ requires photon energy of about $3.2 \mathrm{eV}$ to activate it; which corresponds to the UV radiation [11]. We have calculated the bandgap from the $\mathrm{UV}-\mathrm{V}$ is spectrophotometry (figure 1) these values are compared in table 1. It can be seen the bandgap values do not change much as compared to the reported values of undoped $\mathrm{TiO}_{2}$. Based on that we expect that $\mathrm{TiO}_{2}$ nanotubes possess a rigid structure to dope with nitrogen in the current form of doping.

Table 1: Calculated Bandgap values of the samples treated under $\mathrm{NH}_{3}$ atmosphere at different temperatures.

\begin{tabular}{|c|c|}
\hline Sample & Bandgap (eV) \\
\hline $\mathrm{NH}_{3} / 400^{\circ} \mathrm{C} / 3 \mathrm{~h}$ & 3.2 \\
\hline $\mathrm{NH}_{3} / 500^{\circ} \mathrm{C} / 3 \mathrm{~h}$ & 3.1 \\
\hline $\mathrm{NH}_{3} / 600^{\circ} \mathrm{C} / 3 \mathrm{~h}$ & 3.3 \\
\hline
\end{tabular}


Figure 2 shows the linear sweep voltammetry (LSV) curves of doped $\mathrm{TiO}_{2}$ samples at different temperatures under $\mathrm{NH}_{3}$ atmosphere. To evaluate the light activated response of the samples, the LSV was performed in light incidence and light blocking after every successive five second. It is possible to observe that all the samples present photocurrent response in the presence of light, and when the light is chopped the photocurrent disappears. When irradiating the system with a sufficient photon energy that is equal or greater than the bandgap, the electrons from the conduction band jumps to the valence band of the semiconductor. For N-type semiconductors, the applied biasing is such that these electrons move towards the counter electrode. The holes that are generated in the semiconductor move towards the surface of the semiconductor where they oxidize the nearby species. Since, we are using here the redox couple, that oxidizes before the water oxidation; therefore, in the current study oxygen is not produced. On the other hand, hydrogen is produced on the counter electrode [3], [12].

Hence, the photocurrent produced here is the result of the chemical reaction that occurs on the working electrode and as well as on the counter electrode. Furthermore, figure 3 clearly indicates the influence of the nitridation temperature on the photocurrent response. The lowest performance is obtained from the $\mathrm{TiO}_{2}$ nanotubes doped with nitrogen, by heat treatment under ammonia environment at $600{ }^{\circ} \mathrm{C}$ and it is in accordance to the result obtained in the UV-vis analyses (figure 2), where the sample heat treated at $600{ }^{\circ} \mathrm{C}$ clearly indicates an absorption shoulder at lower photon energies. These results indicate that for photoelectrochemical hydrogen production doping $\mathrm{TiO}_{2}$ with $\mathrm{N}$ at higher temperature creates intermediate bandgap states that act as recombination states for electron-hole pairs. Therefore, we suggest that in order to obtain improved photocurrent $\mathrm{TiO}_{2}$ should be heat treated under ammonia at low temperature.

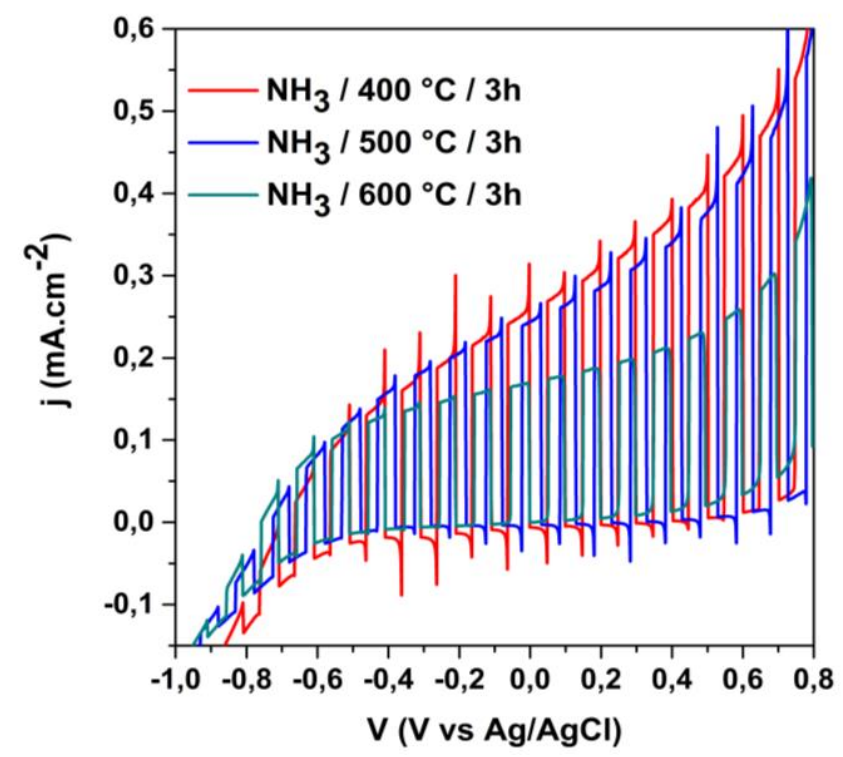

Figure 3: Linear sweep voltammetry curves of $\mathrm{N}$-doped $\mathrm{TiO}_{2}$ nanotubular electrodes under simulated irradiation (AM 1.5 G, 1 Sun) at a rate of $10 \mathrm{mV} / \mathrm{s}$ with an interval of five seconds of light chopping.

\section{Conclusion}

In this work, we have synthesized $\mathrm{TiO}_{2}$ nanotubes by anodization process. In order to dope these amorphous nanotubes with nitrogen, we have heat-treated the samples under the ammonia environment. We have found that the heat treatment temperature strongly influence the morphology and the light absorption from $\mathrm{TiO}_{2}$ nanotubes under ammonia environment, which has a direct effect on the photoelectrochemical performance of the electrodes. Based on the results obtained in the present work it can be concluded that the sample that underwent thermal treatment in ammonia atmosphere at lower temperature is a promising photoelectrode. On the other hand, higher temperature treatment creates intermediate states that act as a recombination centers for photogenerated electronhole pairs, and hence the photocurrent decreases. Therefore, in order to obtain higher current and lower defects, it is necessary lower heat treatment temperature to dope amorphous $\mathrm{TiO}_{2}$ nanotubes with nitrogen. $\mathrm{TiO}_{2}$ nanotubes doped with nitrogen can be applied in dye sensitized solar cells and other titanium dioxide based heterostructures.

\section{Acknowledgement}

This work was carried out with the support of CAPES, a Brazilian Government entity focused on Human Resources formation. We also thank PGMAT/UCS, for carrying out the FEG analysis.

\section{References}

[1] K. Nakata, A Fujishima, " $\mathrm{TiO}_{2}$ photocatalysis: design and applications." J. Photochem. Photobiol. C photochem. Rev. (2012);13:169-189.

[2] A. Kudo, Y. Received. "Renewable energy issue energy research." Chem. Soc. Rev. (2008); 38: 253-278.

[3] S. Khan, M. "Pristine Ta3N5 Nanotubes: Trap-Driven High External Biasing Perspective in Semiconductor/Electrolyte Interfaces". Chermistry a European Journal. (2016); 22: 1850118511.

[4] J. Fernandes, P. Migowski, Z. Fabrim et al. "Magnetron sputtering for photoelectrochemical applications under visible light irradiation." Phys. Chem. (2014); 9148-9153.

[5] B. Yuana, Y. Wang. "Nitrogen doped $\mathrm{TiO}_{2}$ nanotube arrays with high photoelectrochemical activity for photocatalytic applications Applied Surface". Science (2013); 280: 523- 529.

[6] L. Haijin, L. Guoguang. “ $G d^{3+} \mathrm{N}$-codoped trititanate nanotubes: preparation, characterization and photocatalytic activity". Applied Surface Science (2011); 257: 3728-3732.

[7] R. Yerga, M. Galván. "Water Splitting on Semiconductor Catalysts under Visible- Light Irradiation." ChemSusChem (2009); 2: $471-485$. 
[8] T. dos Santos, K. Sherdil. "Efeito de potencial de anodização na propriedade fotoeletroquímica de nanotubos de $\mathrm{TiO}_{2}$." 71으 Congresso Anual da ABM (2006).

[9] S. Khan, M. Zapata. "Effect of oxygen content on the photoelectrochemical activity of crystallographically preferred oriented Porous $\mathrm{Ta}_{3} \mathrm{~N}_{5}$ nanotubes". J. Phys. Chem. C (2015); 119: 19906-19914.

[10] J. Fernandes, E. Kohlrausch "Effect of anodisation time and thermal treatment temperature on the structural and photoelectrochemical properties of $\mathrm{TiO}_{2}$ nanotubes". Solid State Chemistry (2017); 251: 217-223.

[11] E. Kohlrausch, M. Zapata. "Polymorphic phase study on nitrogen-doped $\mathrm{TiO}_{2}$ nanoparticles: effect on oxygen site occupancy, dye sensitized solar cells efficiency and hydrogen production." (2015); 123.

[12] S. Khan, M. Zapata. "Structural, optical and photoelectrochemical characterizations of monoclinic $\mathrm{Ta}_{3} \mathrm{~N}_{5}$ thin films." Physical Chemistry (2015); 37: 23677-24480. 